\title{
An Alternative to Conceptual Analysis IN THE FunCTION DEBATE
}

\section{INTRODUCTION}

Philosophical interest in the biological concept of function stems largely from concerns about its teleological associations. Assigning something a function seems akin to assigning it a purpose, and discussion of the purpose of items has long been off-limits to science. Analytic philosophers have attempted to defend 'function' by showing that claims about functions do not involve any reference to a problematic notion of purpose. To do this, philosophers offer short lists of necessary and sufficient conditions for the application of the concept-where the conditions involve only acceptable physical or biological notions - and claim that the set of conditions captures the import of function statements.

One problem is that no such set of conditions fits biological use perfectly, and debate among the various approaches rages. Proposals can be separated into two main categories. Etiological accounts include a condition referring to the natural selection of the trait in question, while Non-etiological accounts abjure any such reference. Now, thirty years after the Etiological approach first attracted widespread support (after Wright [1973]), the two sides remain at odds. Perhaps most importantly, some real-life cases and thought experiments appear to show that Etiological accounts limit function ascriptions unacceptably, while other cases suggest that Non-etiological accounts assign functions too liberally. Sadly, the debate over how to handle such cases, and whether modified accounts can avoid them, often degenerates into the "dull thud of conflicting intuitions" (to borrow an apt phrase from Bigelow and Pargetter 1987, p. 196).

In this paper, I claim that the standoff between the two sides stems largely from the assumption that the project is conceptual analysis, where accounts attempt to state the intension or extension of the current biological term or to describe biologists' criteria for its application. This sort of project relies on

"An Alternative to Conceptual Analysis in the Function Debate" by Peter H. Schwartz, The Monist, vol. 87, no. 1, pp. 136-153. Copyright @ 2004, THE MONIST, Peru, Illinois 61354. 
questionable psychological and philosophical presumptions, however, and I propose that philosophers should drop the idea that the analysis of function is a project of this type. Instead, the various accounts should be judged as proposed definitions for new concepts, and accounts should be evaluated for whether these new concepts could carry out certain important theoretical roles in biology. Although this "pragmatic move" has been made many times in the history of philosophy and science, this sort of pragmatism has not been adequately appreciated in the function debate and in the philosophy of biology more generally.

The paper proceeds as follows. I begin in Section I by sketching three accounts of function. In Section II, I show how the distinction between them is epitomized by the debate over how to assign functions to the rear flippers of the sea turtle. In Section III, I provide an overview of the reasons why the idea of conceptual analysis has come under fire from psychological research and philosophical questions about meaning. In Section IV, I describe my alternative to conceptual analysis. In Section V, I describe earlier proposals in the function debate of alternatives to conceptual analysis and compare them with my proposal. In the Conclusion, I draw some lessons for thinking about the relation between the functions of living things and those of artifacts. ${ }^{1}$

\section{ACCOUNTS OF FunCtion}

\subsection{Two accounts of function:}

Accounts of function in analytic philosophy have focused on distinguishing between an item's effects and its functions; the lion's heart has many effects - making certain sounds, moving blood in certain ways-but pumping, and not thumping, counts as its function. Early philosophical accounts claimed that functions are those effects that are necessary for survival and reproduction, and this sort of approach can be called the "Survival and Reproduction" (SR) account. As Bigelow and Pargetter (1987) put it: an effect of a trait is a function just as long as "it confers a survival enhancing propensity on a creature that possesses it" (p. 192). ${ }^{2}$

Theories of this sort have been challenged by cases that suggest that they assign functions too liberally. For example, the SR account has the consequence that the human nose has the function of holding up glasses and the 
human heart has the function of alerting doctors to dangerous ailments (Wright 1973, p. 148). An SR account would give the weight of a flying fish the function of returning it to the water (Williams 1966, pp. 11-12). These and other problems led some theorists to adopt the "Natural Selection" (NS) account (as I'll call it): a trait only has a function F if it was favored by natural selection for doing F. According to NS, the nose doesn't have the function of holding up glasses since it was never favored by selection for doing this. ${ }^{3}$

But while SR accounts face the charge of assigning functions too liberally, NS accounts have to confront cases in which they appear too stringent. Christopher Boorse (1976, pp. 74-75) first presented the thought experiment of "Accidental Animals" (as I'll call it): Imagine that the lion species did not exist, and then an individual lion came into being due to a random collision of molecules. According to NS, its "heart" would not have the function of pumping blood, since it was never favored by selection for doing this, and this conflicts with intuitions that it should count as having this function, despite its unusual history. Critics of Etiological accounts have utilized this sort of thought experiment a number of times with some twists. ${ }^{4}$ Responses by Etiological theorists have either questioned the relevance of such imaginary cases (e.g., Millikan 1989) or argued that we should accept the initially counterintuitive conclusion that such organs are functionless (e.g., Neander 1991a).

\subsection{Pluralism:}

In addition, some Etiological theorists have accepted that the traits of accidental animals can be said to have functions in some sense. The "Pluralist account," as I'll call it, proposes that there are two (or more) concepts of function in biology, one defined etiologically and the other non-etiologically (e.g., Millikan 1989, Neander 1991a, b; Godfrey-Smith 1993, 1994). Since these theories claim that at least one concept in biology is defined by an Etiological account, I will count them as Etiological theories, and I'll focus on this form of the Etioloical account for the rest of the paper. Various names for the two concepts have been proposed: I'll follow those who call the etiological concept "proper function" and the non-etiological one "causalrole function."5 For the purposes of this paper, I will consider a Pluralist account where the concept of proper function is defined by an NS account, while the concept of causal-role function is defined by the SR account. ${ }^{6}$ 
Pluralism must provide some explanation of how to tell when one or the other concept of function is at work in biology, and different theorists have proposed different tests. Millikan (1989) and Neander (1991a) write that "proper function" plays two key theoretical roles that "causal-role function" cannot; if an occurrence of "function" is playing one of these roles, then it should be taken to mean "proper function." The first role is placing items in functional categories like 'heart'. An item is a heart, they argue, only if it has the proper function of pumping blood. Just having the causalrole function of pumping blood is not sufficient to make something a heart: an organ that happens to pump blood due to a unique mutation, and thus has this causal-role function but not proper function, is not a heart, they argue. Similarly, it is not necessary for an item to have the causal-role function of pumping blood to be a heart: some objects are still hearts even though they cannot pump blood, such as those which are "atrophied, clogged, congenitally malformed, or sliced in two" (Neander 1991a, p. 180). These are still hearts, just dysfunctional ones.

This leads to the second role for "proper function," of determining which states of an organism count as dysfunctional. A trait-token will only count as dysfunctional if it fails to carry out the proper function of its trait-type, not if it has simply stopped carrying out a beneficial causal-role function. Similarly, a piece of driftwood can serve as a paddle, and may even be said to have this function in some sense, but it would be peculiar to say that it is a paddle or to say that it is a dysfunctional paddle since it has broken in half (following Millikan 1989, p. 295). ${ }^{7}$

Thus we can see how Pluralism will interpret the case of accidental animals. The "heart" of accidental lions has the causal-role function of pumping blood, contributing in certain ways to survival and reproduction, but doesn't have this proper function. Thus it is not really a heart at all, despite initial appearances. If the "heart" were to stop, it would not be dysfunctioning. The SR account, in contrast, would count the accidental animal as having a heart and would judge it as dysfunctional if it stopped.

Is there a way to tell which of these implications about the "hearts" of accidental animals is correct? It seems that intuitions can be led either way, and thus the "dull thud of conflicting intuitions" threatens (c.f. Bigelow and Pargetter [1987, p. 188]), and Neander [1991a, pp. 179-80]). What we need is a real-life case where we can see what biologists actually say, which leads us to the rear flippers of sea turtles. 


\section{The Case of the Rear Flippers of Sea Turtles:}

Sea turtles exhibit many features that are well-suited to their aquatic lifestyle. The legs of their amphibious ancestors have lengthened and broadened into flippers that propel and guide the animals through water. Given the extensive associated modifications, including changes in muscles, bones, and skin, it is clear that natural selection has been responsible for at least some of these changes (Hirayama 1998). ${ }^{8}$ But the rear flippers also play another crucial role in the species: digging a hole in which females hide and protect eggs until hatching (c.f. LeBuff [1990, pp. 62-64] and Kuchling [1999, pp. 83-84]).

The rear legs' role in digging, unlike their role in swimming, may never have been favored by selection over alternatives for playing this role. This is because in order for selection to occur there must be a difference in fitness based on heritable variation in ability to achieve the important effect (Lewontin 1970, 1978, Sober 1993). If there has been no heritable variation in sea turtle flippers in their ability to dig, then there has been no selection among flippers for digging. 9 Thus, according to Pluralism, aiding swimming is a proper function (and a causal-role function) of the limbs, while digging is just a causal-role function. In contrast, the SR account does not acknowledge a crucial distinction between these two functions.

Thus the rear flippers appear to be a good test case to examine the difference between the theories (our representative Etiological and Nonetiological accounts), and the case has attracted attention because of this. Other examples of "exaptations"-traits that play useful roles that may never have been favored by selection-can serve as well. ${ }^{10}$ Some fishing birds hold their wings out to the side to cast a shadow that highlights their prey in the water below them, and this "mantling" has been described as a paradigm exaptation since there is no evidence that selection has acted to favor the wings' playing this role (Gould and Vrba 1982, pp. 7-8; Millikan 1993, p. 44). Another claimed paradigm exaptation has been the role of the sutures in the human skull in easing the baby's transit down the birth canal. Here I will concentrate on the case of the sea turtle's rear flippers, but similar points could be made about these other cases.

When Millikan (1993) initially highlighted the sea turtle flippers in the function debate, she argued that it is unacceptable that the flippers should fail to count as having the proper function of digging, and she pro- 
posed extending the definition of 'proper function' to include cases like this, as follows. Although the flippers were never favored by selection for digging, they crucially played this role during the selection of other traits, and she proposed that this should be enough to ascribe a trait a proper function (1993, p. 48). But this proposal runs into the same problems with liberality that the SR account initially faced (Preston 1998) - the weight of the flying fish might have the proper function of returning the fish to water-and Millikan (1999) has dropped the proposal. It looks like the Pluralist account has to be comfortable with the idea that exaptations have only causal-role functions. But is this tenable?

Because the sea turtle flippers are a real-life case, we have the option of consulting the biological literature, rather than our perhaps unreliable intuitions. And given the two specific roles of proper functions-assigning items to functional categories and determining which conditions count as dysfunctional-there are two specific implications to check. First, the flippers should not be placed in a functional category based on their digging, and this seems to be correct. The limbs are flippers after all, based on their proper function of propelling and guiding movement through water, not "diggers." A review of the biological literature shows that biological usage accords with this; although it is acknowledged that back limbs dig, they are not described as "diggers" or anything similar."11 Pluralism works so far.

The second consequence of Pluralism, concerning dysfunction, raises more complications. The implication is that if a sea turtle's rear flippers could propel the animal through water but could not dig, they would not count as dysfunctional. We must note that the relevant case is relatively specific, for the following reasons. Consider a flipper that cannot aid in swimming or digging: this flipper could be counted as dysfunctional based on its failure to carry out the proper function of swimming. Pluralism will only block the attribution of dysfunction if the flipper aids swimming successfully but can't accomplish digging. And a review of the literature again shows no cases that conflict with this relatively narrow consequence..$^{12}$

A critic of the Etiological approach could still appeal to a lingering sense that biologists would count a flipper of this sort as dysfunctional, and one could probably find biologists who would agree. On the other hand, we might also find biologists who disagree, and agree with Pluralism's conclusions that such flippers would not be dysfunctional. More commonly, 
biologists will become impatient with the whole discussion, seeing the question as pointless. The dangers of irresolvable conflict, and seemingly unimportant semantic debate, looms.

So even though the turtle flippers present a real-life case, discussion leads to stalemate over intuitions again. I believe that this case and others like it show that deciding on an account of function should not be taken as making a claim about the current concept of function at work in biology. Instead, choosing an account requires deciding how to draw lines that have never been present in biology before.

\section{Conceptual Analysis and its Problems}

The "dull thud of conflicting intuitions" that arises in the function debate should be familiar from other areas of analytic philosophy attempting conceptual analysis. Discussions of everything from "justice" in moral philosophy to "justification" in epistemology are beset by standoffs over how to interpret thought experiments and problem cases. And there is good evidence that problems with the project of conceptual analysisconcerning its psychological and philosophical presuppositions-lead to these quagmires. Philosophers have started to recognize these problems in these other areas, and I wish to raise some of these same concerns for the function debate (cf. Ramsey 1992, DePaul and Ramsey 1998, Brown 1999, Stitch 1998).

Three aspects of the function debate fit the model of conceptual analysis quite well. First, proposed accounts of the concept are formulated as a short list of individually necessary and jointly sufficient conditions for applying it. Secondly, accounts are tested by examining whether they apply in a range of real and imaginary situations. Lastly, accounts often explicitly aim at uncovering the meaning of the concept in question. In their classic papers, Wright (1973, p. 161) and Boorse (1976, p. 82) present their theories as analyses of what "the function of X is F means" (My underlining and renaming of variables).

Philosophers have identified two sets of problems with the project of conceptual analysis. One set stems from inadequacies of the "classic conception of concepts," the idea that concepts can be represented by a short list of relatively simple criteria for their application (Ramsey 1992). Psychologists have found that speakers do not appear to apply concepts according 
to a set of individually necessary and jointly sufficient conditions (cf. Ramsey 1992, Rosch and Mervis 1975). First, in many cases, no single characteristic is shared by all members of the extension; that is, important properties for classifying an item under a given concept do not appear to be necessary ones. For example, although flying counts as an important property for classifying many animals as birds, some animals, such as ostriches, are recognized as birds even though they can't fly.

Second, membership in an extension does not appear to be all-ornothing, as it is for the classic conception. Falcons are better examples of birds than ostriches, and this ordering of items is reflected by multiple different measures. Better examples are learned more easily, come to mind more quickly, and influence thought more powerfully (Ramsey 1992, p. 630).

These two findings have led many psychologists to adopt a model of concepts that accords with Wittgenstein's (1953) "family resemblance." And this suggests that the search for a definition in the form of short list of relatively simple conditions that are individually necessary and jointly sufficient will not fit actual use by competent speakers.

Philosophers committed to conceptual analysis, though, may well respond that they are not interested in the application of concepts by competent speakers, but instead in the meaning of concepts. But the assumed idea of meaning has faced increasingly sharp questioning by analytic philosophers. If the meaning of a concept could be specified precisely, then each true statement involving the concept could be classified as analytic or synthetic. And the attack on the analytic/synthetic distinction, by Quine (1953, 1961), Putnam $(1961,1975)$ and others, thus undermines the idea that meaning can be specified so precisely. Putnam (1961), for example, points out that kinetic energy was originally defined by the equation " $\mathrm{e}=1 / 2$ mv2" and thus began as an analytic truth. Later, arguments for relativity theory disproved this equation, suggesting that at some point it had become a synthetic claim. Forcing all scientific beliefs into one or the other category - "analytic" or "synthetic"-will warp the philosophical understanding of science, Putnam argues convincingly.

\section{Philosophical Explication}

Avoiding the problems of conceptual analysis requires adopting a new sort of philosophical project, one that avoids any claim to be uncov- 
ering meanings. The project of philosophical explication, as I will call it, resembles proposals made multiple times in the history of philosophy and science, perhaps most importantly in recent analytic philosophy by Carnap (1950, pp. 3-8) and Quine (1961, pp. 257-62).13 Quine (1961, p. 260) writes that philosophical analysis begins with the recognition that a useful expression is also "somehow troublesome": " . . . it is vague in ways that bother us," he writes, "or it puts kinks in a theory or encourages one or another confusion" (p. 260). Philosophers therefore propose new definitions for the expression that would allow it to continue to be useful without raising the problems. Quine describes the project clearly as replacing old terms with new ones:

We do not claim synonymy. We do not claim to make clear and explicit what the users of the unclear expression had unconsciously in mind all along. We do not expose hidden meanings, as the words 'analysis' and 'explication' would suggest; we supply lacks. We fix on the particular functions of the unclear expression that make it worth troubling about, and then devise a substitute, clear and couched in terms to our liking, that fills those functions. (pp. 258-59)

Quine's recommendation mirrors the pragmatic approach of much current philosophy of science, even if the details of his overall philosophical project do not.

Applying this to the function debate eliminates the idea that philosophers are attempting to capture some meaning already present in biology's concepts. The analysis of function began, as mentioned at the beginning of this paper, with the concern that the concept has problematic teleological associations. Considered as philosophical explications, Pluralism and the SR account should be evaluated as proposed definitions of new terms that can allegedly do the work of the old term but without the problems. ${ }^{14}$ Thus it is not surprising that any account will require some modification or clarification of biological usage. Pluralism's specification of particular theoretical roles that the two concepts of function play fits quite well with considering it as a proposed philosophical explication.

The success of a philosophical explication of 'function' will not depend on anyone's adopting and strictly following the definition from some point forward. Biologists may continue to use the word 'function' in ambiguous and even self-contradictory ways, and such use may have various metaphorical or heuristic advantages. But in order for a function claim to be taken literally, the biologist should be willing to adopt a precise definition and present evidence that the relevant conditions are satisfied. 
The availability of an account that could eliminate the vagueness and problematic teleological associations of 'function', while allowing biological science to proceed roughly unchanged, would provide an answer of sorts to the concerns that began the investigation. Since a philosophical explication is not an account of current use or meaning, it stays silent on the question of whether the current biological concept has teleological overtones or involves teleological analogies. It simply establishes that the practice of assigning functions can continue without assuming or implying any unacceptable teleological notions. And this should be enough, I believe, to answer the concerns that started the investigation.

The availability of two (or more) incompatible accounts would similarly answer the original set of concerns. In this case, biologists would be free to choose either account to explain the literal meaning of their terms. As long as we are looking for a way to replace traditional, problematic concepts with new, useful ones, two options are as good (if not better) than one. If the analysis of 'function' was conceptual analysis, the existence of two incompatible accounts would not be an acceptable conclusion to the discussion.

Changing our understanding of the overall project thus changes our approach to the case of the sea turtles' rear flippers. In short, there is no answer to the question of whether the sea turtles' flippers really have this function and whether they have this function in a sense that is really different from their function of aiding swimming. Adopting the SR account, and deciding that the flippers do have the function of digging and swimming, or adopting the Pluralist account and deciding that digging is only a causal role function, reflects a decision about how to speak in the future, not a discovery about biological facts or the content of biological notions. Adopting either theory will clarify, in one way or another, something that was previously vague.

\section{Previous Proposals}

Two important papers on "function" have described the problems with traditional conceptual analysis and proposed alternative ways to model the debate (Millikan 1989, Neander 1991a). Here I will review how my proposal relates to these earlier accounts.

Neander (1991a) calls her analysis of function "conceptual analysis," but disavows any claim to be uncovering meaning. Instead, she says she is 
"... trying to describe the criteria of application that the members of the linguistic community generally have (implicitly or explicitly) in mind when they use the term" (p. 170). She rejects any a priori assumption that the criteria should be stated as a list of necessary and sufficient conditions, and she accepts that the criteria may be based on "family resemblance, similarity to prototypes, or Minskian frames" (p. 171). That said, she presents her own account of "proper function" as a two-part sufficient condition for the application of the term (p. 174).

The biggest problem with characterizing the project as a search for criteria of application in people's minds is that it suggests the need for psychological rather than philosophical investigation. As mentioned above, and as Neander admits, such investigations usually find criteria based on similarity to prototypes rather than traditional necessary and sufficient conditions (e.g., Rosch and Mervis 1975). In addition, here as in other areas competent speakers may not all share a single set of criteria. Neander claims that the dangers are minimized in the case of 'function' since, " . . the relevant linguistic community consists of specialists, and the term under analysis is one of their specialist terms, and is also abstract (non-perceptual) and is embedded in well-articulated theory, ..." (171). For example, Neander points out, chemists all use the same criteria for 'water', i.e., "liquid with molecular structure нон" (172).

The analogy with 'water' should not reassure, however. Although chemists all explicitly learn and accept the definition Neander describes, this is not the case with biologists' use of 'function'. In fact, the lack of a commonly accepted definition fuels the concerns over teleological associations and vagueness that motivated the philosophical project in the first place. Finally, the term 'proper function', which Neander explicates, is an expression introduced by philosophers, not biologists (Millikan 1984, 1989; Neander 1991a), as discussed above.

There is a point of view from which Neander's methodology would be more consistent with her stated goal. Perhaps she imagines that her arguments and cases would convince a biologist that he has had the criteria for proper function "in mind" in some sense all along. This seems possible partly since Neander is not presenting any new biological facts, per se, so in some sense she is not telling the biologist anything that he didn't already know. On the other hand, the arguments could be seen as leading the biologist to adopt a new, more precise, criterion. My characterization of philosophical 
explication avoids this debate entirely: at the conclusion the biologist accepts a definition, and thus a criterion for application, that he or she never explicitly recognized before. There is no need to add the claim that this refinement is a discovery.

Millikan (1984) initially presents her definition of 'proper function' as stipulation, simply a tool in the statement of her philosophical views. She says that it allows her to draw attention to some analogies among a wide range of things, including traits of animals, behaviors, man-made artifacts, and language (1984, p. 38). She writes, "My program is far removed from conceptual analysis; I need a term that will do a certain job and so I must fashion one" (1984, p. 2). Later (1989), she argues that in fact her account is a good "theoretical definition" of the term 'function' in biology in certain contexts. She adamantly rejects any association with an idea of conceptual analysis, and instead characterizes her claim as follows,

A theoretical definition is the sort the scientist gives you in saying that water is $\mathrm{HOH}$, that gold is the element with atomic number 79, or that consumption was, in reality, several varieties of respiratory disease, the chief being tuberculosis, which is an infection caused by the bacterium bacillus tuberculosis. $(1989$, p. 291)

More specifically, she writes, 15

My claim is that actual body organs and systems, actual actions and purposive behaviors, artifacts, words and grammatical forms, and many customs, etc., all have proper functions, and that these proper functions correspond to their functions or purposes ordinarily so called. Further, it is because each of these has a proper function or set of proper functions that it has whatever marks we tend to go by in claiming that it has functions, a purpose, or purposes. (p. 293, her italics)

She adamantly rejects representing her position as a claim about the content of concepts currently at work in biology, instead modeling her claims as concerning the phenomena (Millikan 1999, 2002).

I believe that my approach is largely compatible with hers as well, but philosophical explication disavows some claims that might be implied by her approach. For example, the analogies with definitions of 'water' and 'gold' have to be handled carefully. Some accounts of natural-kind terms claim that their extensions are discovered by science and that the terms had their modern extensions even before anybody knew it. As Putnam (1975) 
famously claims, Archimedes' term that we translate as 'gold' referred to the kind gold-i.e., all and only atoms with atomic number 79-long before modern chemistry arose. ${ }^{16}$ I would prefer to avoid any such implications in the setting of the debate over function, as well as any claim that items with proper functions form some sort of natural kind. Millikan would also disavow such claims, I believe (Millikan 2002 and personal communication). Deciding on the extension of a natural kind may well involve using stipulation to introduce new, sharp boundaries.

Thus, the project of philosophical explication builds on the proposals of Millikan (1989) and Neander (1991a) but avoids possible implications of their views. By presenting my account and comparing it with theirs, I hope to advance a discussion that they began in the function debate, a discussion which has not been pursued sufficiently since then. In this and other areas of philosophy, failing to articulate the goals of the philosophical analysis undermines the quality of the discussion.

\section{CONCLUSION}

As may be clear, I believe that the Pluralist approach roughly sketched above can provide an adequate philosophical explication of 'function' in biology, although I believe that an SR account (properly specified) might offer a tenable alternative. This means there may be no fact of the matter whether the rear flippers of sea turtles have the function of digging in the same sense as they have the function of aiding swimming. And this should not be surprising, given the inherent vagueness in deciding on the precise meaning of any word. The Pluralist account's alternating classification of the flippers' digging - first as proper function in Millikan (1993) and then as causal-role function in Millikan (1999)_reflects vagueness in the current notion of function, which would only be eliminated by accepting one or another philosophical explication.

Understanding this vagueness requires recognizing the metaphorical idea of design that lurks behind the biological notion of function. Prototypical adaptations appear as if they were designed to accomplish their end, even though it's generally accepted that natural selection is not literally a designer. ${ }^{17}$ This remains a very controversial area, and deciding whether natural selection is literally a type of design may require choosing a philosophical explication of the idea of "design." Because of the ambiguous relation 
between natural selection and design, it's unclear how much importance to put, when assigning functions, on the fact that selection occurred or not. And this is part of the reason for the vagueness in interpreting the functions of exaptations, I believe.

The metaphorical idea of design lurking behind ideas of natural selection also provides a useful way to understand the link between artifact and biological functions. Since both the Pluralist and the Survival and Reproduction accounts refer to biological notions, they cannot serve as philosophical explications of the notion of function as applied to human artifacts. A separate theory will be necessary for artifacts, although there will most likely be important analogies between the two realms. For example, an account analogous to Pluralism would distinguish between the aspects of artifacts that are designed and those that are not and would identify particular theoretical roles for the different notions. Thinking about these links may require a further exploration of metaphorical thinking, even though assigning a function in each area can be perfectly literal. Theories in both areas should be evaluated as proposed philosophical explications, not conceptual analyses.

Peter H. Schwartz

Boston University

\section{Notes}

1. I would like to thank Gary Ebbs, Gary Hatfield, Ruth Millikan, Shari Rudavsky, and Alfred Tauber for discussion of topics related to this paper.

2. Some examples of SR accounts include Hempel (1965), Boorse (1976, 2002), and Buller (1998). I cannot do justice here to the important differences between these accounts, especially as regards functions outside of biology.

3. Examples of NS accounts include Ruse (1971) and Wright (1973, 1976). As I will discuss below, I also place "Pluralist" accounts in this group. Again I cannot do justice here to the parts of these accounts that go beyond biology, or to the differences among them.

4. E.g., see Bigelow and Pargetter (1987, p. 188) where they imagine the possibility that the whole world came into existence five minutes ago.

5. Millikan (1989) proposes the terms 'proper function' and 'Cummins function' for the two concepts. Neander (1991a, b), Griffiths $(1992,1993)$, and Preston (1998) adopt 'proper function' for the etiological concept, but for the non-etiological concept Neander (1991a, b) uses 'causal role function' and Preston (1998) uses 'system function'. GodfreySmith (1993) calls the two concepts 'Wright function' and 'Cummins function'. Philosophers have been free to propose terms for the two concepts since philosophers, not biologists, 
were the first to propound such a clear distinction between two concepts of function in biology.

6. Pluralist accounts actually define the non-etiological notion following Cummins (1975), which differs from the SR account in important ways. The Cummins account, however, makes the same assignment of functions as the SR account in the cases considered in this paper, so my simplifying assumption does not affect my consideration of Pluralism here.

7. Pluralists have proposed other ways to distinguish between 'proper function' and 'causal role function'. Millikan (1989, p. 294) points to an association between 'proper function' and ideas of purpose, while Neander (1991a, p. 180; 1991b, p. 454) points to links to normativity. In Godfrey-Smith's $(1993,1994)$ version of Pluralism, the distinction between the two types of function depends on the explanatory goals of the context in which the term is used. I believe these ways of distinguishing between the two concepts of function are less attractive than an approach that focuses on theoretical roles, and I will not discuss them further here.

8. I discuss and defend the "weak adaptationism" involved here in Schwartz (1999b, 2002).

9. The flippers could be maintained by selection for digging, if heritably different flippers arise occasionally that dig less well and are eliminated because of this. But without any evidence of such variation, biologists cannot assume the occurrence of such maintenance selection (or "stabilizing selection," as some biologists call it). I discuss these issues at more length in Schwartz (1999b, 2002).

10. There has been a good deal of controversy over the precise definition of 'exaptation' and the prevalence of exaptations in the biological world. C.f. Preston (1998), Dennett $(1995,1998)$, and Millikan $(1999,2002)$, for example.

11. The review was conducted using the Biological Sciences database of the Cambridge Scientific Abstracts, an electronic index of the biological literature since 1982. Admittedly, I cannot be confident that the search was absolutely complete, but the burden would now fall on critics to produce cases that conflict with Pluralism's implications.

12. This review again utilized the Biological Sciences database of the Cambridge Scientific Abstracts.

13. Gary Ebbs has recently utilized a similar project in philosophy of language (2002), and he first recommended the Quinean approach to me (personal communication). Ramsey $(1992,69)$ also mentions Carnap's (1950) approach as a possible response to problems with conceptual analysis. I presented an earlier version of this paper at a session of the Boston Colloquium for Philosophy of Science in November 2001, where Philip Kitcher proposed a similar account of an alternative to conceptual analysis.

14. I will mostly speak of philosophical explications as proposed definitions of terms, but in places I will also speak of concepts. I will use the notational practice of using single quotation marks to mention a term. Context will clearly indicate when a word is meant to mention a concept.

15. Millikan's (1984) more precise account of "theoretical definition"- -her "theoretical definition of 'theoretical definition'," as she calls it $(1989$, p. 291, n. 2)-is not useful in the present context since it utilizes the concept of proper function (as she points out [ibid]).

16. This claim has been controversial. See, e.g., Donnellan (1983) and Ebbs (1997, pp. 204-15; 2000).

17. Dawkins (1982) for example defends the claim that living things appear as if they were designed, even if we know that their complex organs arose by natural selection and know 
that natural selection is not literally a designer. I address these associations between natural selection and metaphorical ideas of design in my dissertation (Schwartz 1999a, ch. 2).

\section{REFERENCES}

Amundson, Ron and George V. Lauder (1994), "Function Without Purpose: The Uses of Causal Role Function in Evolutionary Biology," Biology and Philosophy 9: 443-69.

Ariew, André, Robert Cummins, and Mark Perlman (eds.) (2002), Functions: New Readings in the Philosophy of Psychology and Biology. Oxford: Oxford University Press.

Bigelow, John and Robert Pargetter (1987), "Functions," Journal of Philosophy 84: 181-96.

Boorse, Christopher (1976), "Wright on Functions," The Philosophical Review 85: 70-86. (2002), "A Rebuttal on Functions," in Ariew et al. (2002).

Brown, Harold (1999), "Why Do Conceptual Analysts Disagree?" Metaphilosophy 20: 33-59.

Buller, David (1998), "Etiological Theories of Function: A Geographical Survey," Biology and Philosophy 13: 505-27.

Carnap, Rudolf (1950), Logical Foundations of Probability, 2nd ed'n. Chicago: University of Chicago Press.

Cummins, Robert (1975), "Functional Analysis," Journal of Philosophy 72: 741-64.

DePaul, Michael R. and William Ramsey (eds.) (1998), Rethinking Intuition. Lanham, MD: Rowman and Littlefield.

Dennett, Daniel C. (1995), Darwin's Dangerous Idea. New York: Touchstone, Simon \& Schuster.

(1999), "Comments and Criticism: Preston on Exaptation: Herons, Apples, and Eggs," Journal of Philosophy 95: 576-80.

Donnellan, Keith S. (1983), "Kripke and Putnam on Natural-Kind Terms," in C. Ginet and S. Shoemaker (eds.), Knowledge and Mind. Oxford: Oxford University Press, pp. 84-104.

Ebbs, Gary (1997), Rule-Following and Realism. Cambridge, MA: Harvard University Press.

(2000), "The Very Idea of Sameness of Extension Over Time," American Philosophical Quarterly 37: 245-68. (2002), "Learning from Others," Noûs 36: 525-49.

Godfrey-Smith, Peter (1993), "Functions: Consensus Without Unity," Pacific Philosophical Quarterly 74: 196-208.

(1994), "A Modern History Theory of Functions," Noûs 28: 344-62.

Gould, Stephen Jay, and Elisabeth S. Vrba (1982), "Exaptation-a Missing Term in the Science of Form," Paleobiology 8: 4-15.

Griffiths, Paul E. (1993), "Functional Analysis and Proper Functions," British Journal of the Philosophy of Science 44: 409-22.

Hempel, Carl (1965), "The Logic of Functional Analysis," in Aspects of Scientific Explanation and Other Essays in the Philosophy of Science. New York: The Free Press.

Hendrickson, John R. (1980), "The Ecological Strategies of Sea Turtles," American Zoologist 20: 597-608. 
Hirayama, Ren (1998), "Oldest Known Sea Turtle," Nature 392: 705-08.

Lebuff, Charles R., Jr. (1990), The Loggerhead Turtle in the Eastern Golf of Mexico. Sanibel, FL: Caretta Research.

Lewontin, Richard (1970), "The Units of Selection," Annual Review of Ecology and Systematics 1: 1-14. (1978), “Adaptation," Scientific American 239: 213-30.

Millikan, Ruth G. (1984), Language, Thought, and Other Biological Categories. Cambridge, MA: M.I.T. Press.

(1989), "In Defense of Proper Functions," Philosophy of Science 56: 288-302. (1993), "Propensities, Exaptations, and the Brain." In White Queen Psychology and Other Essays for Alice. Cambridge, MA: M.I.T. Press, pp. 31-50. (1999), "Comments and Criticism: Wings, Spoons, Pills, and Quills: A Pluralist Theory of Function," Journal of Philosophy 96: 191-206. (2002), "'Biofunctions: Two Paradigms," in Ariew et al. (2002).

Neander, Karen (1991a), "Functions as Selected Effects: The Conceptual Analyst's Defense," Philosophy of Science 58: 168-84. (1991b), "The Teleological Notion of 'Function'," Australasian Journal of Philosophy 69: 454-68.

Preston, Beth (1998), "Why Is a Wing Like a Spoon? A Pluralist Theory of Function," Journal of Philosophy 95: 215-54.

Putnam, Hilary (1962), "The Analytic and the Synthetic," in H. Feigl and G. Maxwell (eds.), Minnesota Studies in the Philosophy of Science, Vol. 3. Minneapolis, MN: University of Minnesota Press. Reprinted (1975), in Mind, Language and Reality: Philosophical Papers, Vol. 2. Cambridge: Cambridge University Press, pp. 33-69. (1975), "The Meaning of 'Meaning'," in Mind, Language and Reality: Philosophical Papers, Vol. 2. Cambridge: Cambridge University Press, pp. 215-71.

Quine, W. V. O. (1953), "Two Dogmas of Empiricism," in From a Logical Point of View. Cambridge, MA: Harvard University Press, pp. 20-46. (1961), Word and Object, Cambridge, MA: M.I.T. Press.

Ramsey, William (1992), "Prototypes and Conceptual Analysis," Topoi 11: 59-70.

Rosch, Eleanor and Carolyn Mervis (1975), "Family Resemblance: Studies in the Internal Structure of Categories," Cognitive Psychology 8: 382-439. Reprinted in DePaul and Ramsey (1998).

Ruse, Michael (1971), "Functional Statements in Biology," Philosophy of Science 38: 87-95.

Schwartz, Peter H. (1999a), "Function, Dysfunction, and Disease in Biology and Medicine," Ph.D. dissertation, Philosophy Dept., University of Pennsylvania. (1999b), "Proper Function and Recent Selection," Philosophy of Science 66 (Proceedings): S210-S222. (2002), "The Continuing Usefulness Account of Proper Function," in Ariew et al. (2002).

Sober, Elliot (1993), Philosophy of Biology. Boulder, CO: Westview Press.

Stich, Stephen (1998), "Reflective Equilibrium, Analytic Epistemology and the Problem of Cognitive Diversity," in DePaul and Ramsey (1998). Originally published (1988) in Synthese 74: 391-413.

Walsh, Denis M. (1996), "Fitness and Function," British Journal for the Philosophy of Science 47: 553-74. 
Williams, George C. (1966), Adaptation and Natural Selection: A Critique of Some Current Evolutionary Thought. Princeton, NJ: Princeton University Press.

Wittgenstein, Ludwig (1953), Philosophical Investigations. Trans. G. E. M. Anscombe. New York: Macmillan.

Wright, Larry (1973), "Functions," Philosophical Review 82: 139-68. (1976), Teleological Explanations. Berkeley, CA: University of California Press. 